\title{
PENGARUH PENAMBAHAN FLY ASH (ABU TERBANG) DAN ABU SEKAM PADI TERHADAP KUAT TEKAN BATA MERAH PEJAL KONVENSIONAL
}

\author{
Bimo Prakoso ${ }^{1)}$, Elhusna ${ }^{2)}$, Ade Sri Wahyuni ${ }^{3)}$ \\ ${ }^{122) 3)}$ Program Studi Teknik Sipil, Fakultas Teknik UNIB, Jl. W. R. Supratman, \\ Kandang Limun, Bengkulu 38371, Telp. (0736)344087 \\ email: inersia@unib.ac.id
}

\begin{abstract}
Abstrak
Bata merah adalah suatu unsur bangunan yang dipergunakan dalam pembuatan kontruksi bangunan dan dibuat dari tanah liat ditambah air dengan atau tanpa bahan campuran lain. Fly ash dan abu sekam padi mengandung unsur kimia silika.Silika adalah bahan yang mempunyai sifat pozzolan yang bila dicampur dengan tanah dapat menambah kuat tekan bata. Penelitian ini bertujuan untuk mengetahui besarnya pengaruh penambahan fly ash dan abu sekam padi terhadap nilai kuat tekan bata merah. Proses pembuatan benda uji mengikuti prosedur di pabrik bata. Variasi benda uji yang dibuat yaitu bata normal dan bata dengan penambahan fly ash dan abu sekam padi yang digunakan masing-masing adalah 5\%, 10\%, 15\%, 20\%, 25\%, dan 30\% terhadap berat tanah liat. Jumlah benda uji masing-masing persentase penambahan fly ash dan abu sekam padi adalah sebanyak 12 benda uji. Metode pengujian kuat tekan bata merah mengacu pada SNI 15-2094-2000. Berdasarkan hasil penelitian diketahui bahwa nilai kuat tekan bata merah mengalami penurunan dari bata merah normal $\left(38,97 \mathrm{~kg} / \mathrm{cm}^{2}\right)$. Penurunan nilai kuat tekan terbesar terjadi pada bata merah dengan penambahan abu $30 \%(48,04 \%)$ dan penurunan nilai kuat tekan bata terkecil terjadi pada bata merah dengan penambahan abu 5\% (5,98\%). Penurunan nilai kuat tekan dipengaruhi oleh jumlah penambahan abu, jumlah penggunaan air dan kadar air.
\end{abstract}

Kata kunci: bata merah, fly ash, abu sekam padi, kuat tekan

\begin{abstract}
Red brick is a building element used in the construction of buildings and made of clay plus water with or without material mixture of other materials. Fly ash and rice husk ash contain silica. Silica is a material that has the nature of pozzolan which can increase the compressive strength of the brick when mixed with the soil. This study aims to determine the effect of the addition of fly ash and rice husk ash (ASP) to the value of compressive strength of clay brick.The process of making the test specimen follows the procedure in the brick factory.Variations of specimens made were normal bricks and bricks with the addition of fly ash and rice husk ash (ASP) used were 5\%,10\%,15\%,20\%, 25\% and 30\% to the weight of clay.The number of test specimens of each percentage of fly ash and rice husk ash (ASP) as much as 12 specimens. The method of testing of red brick strength is referred to SNI 15-20942000. The result of the research shows that the compressive strength of the clay brick has decreased from normal clay brick by $38,97 \mathrm{~kg} / \mathrm{cm}^{2}$. The biggest decrease in compressive strength value obtaines at clay brick with $30 \%$ ashes $(48,04 \%)$ and the smallest decreased obtaines at clay brick compressive strength in clay brick with 5\% ash (5,98\%). The decrease of the compressive strength is influenced by the amount of ash addition, water quantity and moisture content.
\end{abstract}

Keywords: clay brick, fly ash, rice husk ash,compressive strength

Jurnal Inersia April 2018 Vol.10 No.1

Email:Inersia@unib.ac.id 


\section{PENDAHULUAN}

Bata adalah bangunan yang digunakan sebagai dinding yang merupakan bangunan non struktural yang tidak memikul beban secara langsung. Bata merah memiliki beberapa tahap pengerjaan, seperti menggali bahan, mengolah, mencetak, mengeringkan, membakar pada temperatur tinggi hingga matang dan berubah warna (Kamali, 2014). Bata terbuat dari tanah liat atau dengan bahan campuran lain (SNI 15-2094-2000).

\section{TINJAUAN PUSTAKA}

\section{Tanah liat}

Tanah liat alias lempung merupakan tanah dengan kadar mineral lempung yang tinggi. Tanah liat terbentuk akibat melapuknya batuan silika karena terpengaruh asam karbonat. Ciri khas tanah ini adalah kering, lengket, dan menggumpal dan melunak jika terkena air (Ahira dalam Sari, 2014). Kandungan kimia tanah liat terdiri dari silikon oksida $\left(\mathrm{SiO}_{2}\right)$ sebanyak $47 \%$, aluminium oksida $\left(\mathrm{Al}_{2} \mathrm{O}_{3}\right)$ sebanyak $39 \%$, air $\left(\mathrm{H}_{2} \mathrm{O}\right)$ sebanyak $14 \%$ dan senyawa kimia lainya (Astuti, 1997).

\section{Fly ash}

Fly ash adalah bagian dari sisa pembakaran batu bara pada boiler pembangkit listrik tenaga uap yang berbentuk partikel halus dan bersifat pozzolan. Sifat pozzolan ini berarti fly ash tersebut dapat bereaksi dengan kapur pada suhu kamar $\left(24^{\circ} \mathrm{C}-27^{\circ} \mathrm{C}\right)$ dengan adanya media air membentuk senyawa yang bersifat mengikat. Komposisi unsur pokok fly ash adalah $\mathrm{SiO}_{2}$ (30\%$60 \%), \mathrm{Al}_{2} \mathrm{O}_{3}(15 \%-30 \%)$ dan karbon dalam bentuk batu bara yang tidak terbakar (bervariasi hingga 30\%) (Armeyn, 2014).

\section{Abu sekam padi}

Sekam padi adalah kulit yang membungkus butiran beras, dimana kulit padi akan terpisah dan menjadi limbah atau buangan. Sekam padi dibakar akan menghasilkan abu sekam padi. Abu ini memiliki kandungan silica reaktif sekitar $85 \%-90 \%$ (Ferdyan dan Aswad, 2013).

\section{Air}

Air adalah substansi kimia dengan rumus kimia $\mathrm{H}_{2} \mathrm{O}$. Air adalah bahan yang sangat penting dalam proses reaksi pengikatan matreial-material yang digunakan untuk pembuatan bata (Elianora dkk, 2010).

\section{Kuat tekan bata merah}

Kuat tekan bata merah adalah gayaa maksimum per satuan luas permukaan yang dibebani. SNI 15-2094-2000 menyatakan bahwa besarnya kuat tekan dapat dinyatakan dengan rumus:

$$
\sigma=\frac{\mathrm{P}}{\mathrm{A}}
$$

Keterangan:

$\sigma=$ Kuat tekan bata merah $\left(\mathrm{kg} / \mathrm{cm}^{2}\right)$

$\mathrm{P}=$ Beban maksimum $(\mathrm{kg})$

$\mathrm{A}=$ luas penampang benda uji $\left(\mathrm{cm}^{2}\right)$

\section{METODE PENELITIAN}

Tahapan pelaksanaan penelitian meliputi pemeriksaan bahan campuran bata merah dengan melakukan uji fisis, jumlah penggunaan bahan campuran, pembuatan benda uji bata, pembuatan benda uji tekan dan pelaksanaan pengujian kuat tekan.

\section{Pemeriksaan tanah liat}

Tanah liat yang digunakan dalam penelitian ini berasal di lokasi pabrik bata di Kelurahan Bumi Ayu, Kecamatan Selebar, Kota Bengkulu. Tanah liat yang digunakan telah dikarantina selama 3 minggu supaya tidak terkena hujan dan untuk proses pelapukan bahan organik.

Pengujian sifat fisis tanah liat meliputi:

1. Berat isi (SNI 03-3637-1994)

2. Kadar air (SNI 03-1965-1990)

3. Atterberg limit (SNI 1966-2008)

4. Berat jenis (SNI 1964-2008)

Karakteristik sifat fisis tanah liat dapat dilihat pada Tabel 1 . 
Tabel 1. Karakteristik Tanah Liat

\begin{tabular}{|c|c|c|c|}
\hline No & Uraian & Tanah & Satuan \\
\hline 1 & Berat Isi & 1,27 & $\mathrm{gr} / \mathrm{cm}^{3}$ \\
\hline 2 & Kadar Air & 46,2 & $\%$ \\
\hline \multirow{2}{*}{3} & Batas Cair & 61,83 & $\%$ \\
\cline { 2 - 4 } & Batas Plastis & 47,17 & $\%$ \\
\cline { 2 - 4 } & PI & 43,98 & $\%$ \\
\hline 4 & Berat Jenis & 2,76 & $\mathrm{gr} / \mathrm{cm}^{2}$ \\
\hline
\end{tabular}

\section{Pemeriksaan Abu}

Fly ash yang digunakan dalam penelitian ini diperoleh dari sisa pembakaran batu bara PT. Prima Naya PLTU di Kabupaten Lahat, Provinsi Sumatera Selatan. Abu sekam padi yang digunakan dalam penelitian ini diperoleh dari pabrik penggilingan padi di Arga Makmur, Kabupaten Bengkulu Utara.Fly ash dan Abu sekam padi yang digunakan telah lolos saringan no 100.

Pengujian sifat fisis yang dilakukan pada fly ash dan abu sekam padi meliputi:

1. Berat isi abu (SNI 03-4804-1998)

2. Kadar air SNI (03-1965-1990)

3. Analisa saringan (SNI 3423-2008)

4. Berat jenis (SNI 1964-2008).

Karakteristik sifat fisis abu dapat dilihat pada Tabel 2.

Tabel 2. Karakteristik Abu

\begin{tabular}{|c|c|c|c|c|}
\hline No & Uraian & ASP & FA & Satuan \\
\hline 1 & Berat Isi & 0,30 & 0,99 & $\mathrm{~kg} / \mathrm{lt}$ \\
\hline 2 & Kadar Air & 3,81 & 2,92 & $\%$ \\
\hline 3 & MHB & 0,91 & 0,85 & - \\
\hline 4 & $\begin{array}{c}\text { Berat } \\
\text { Jenis }\end{array}$ & 1,78 & 2,3 & $\mathrm{gr} / \mathrm{cm}^{3}$ \\
\hline
\end{tabular}

\section{Proses pembuatan bata merah}

\section{Tahapan pembuatan bata}

Pembuatan bata merah yang dilakukan yaitu pencetakan bata normal, pencetakan bata penambahan abu masing-masing fly ash dan abu sekam padi $5 \%, 10 \%, 15 \%, 20 \%$, dan $30 \%$. Kebutuhan bahan pembetuk bata tiap variasi adukan dapat dilihat pada Tabel 3 .
Tabel 3. Kebutuhan Bahan Bata tiap Variasi

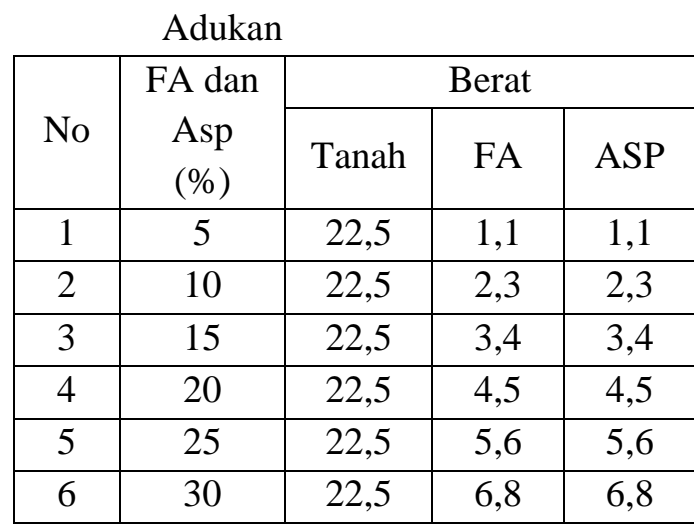

Pencetakan bata merah dilakukan secara manual dan cetakannya terbuat dari kayu dengan ukuran panjang $21,5 \mathrm{~cm}$, lebar 10,5 $\mathrm{cm}$ dan tinggi $5 \mathrm{~cm}$. Cetakan bata merah dilapisi dengan pasir agar adukan bata merah tidak menempel pada cetakan bata.

Pengeringan benda uji bata merah yang telah dicetak disusun terlebih dahulu.Cara pengeringan dilakukan yaitu dengan pengeringan alam (cahaya matahari), menggunakan atap penutup pada bata yang dikeringkan atau menggunakan rak-rak.

Pembakaran bata dilakukan setelah pengeringan selesai. Batu bata dibakar dalam tungku pembakaran. Pembakaran batu merah dilakukan secara bersamaan dengan jumlah bata merah sebanyak 15,000 bata dan berlangsung 72 jam didinginkan selama 24-48 jam.

\section{Pembuatan benda uji tekan}

Pembuatan benda uji tekan bata dilakukan menurut SNI 15-2094-2000 adalah sebagai berikut:

1. Bata dipotong menjadi dua bagian sama panjang menggunakan gergaji besi.

2. Siapkan adukan mortar dengan perbandingan 1 PC : 3 PS yaitu 1 wadah semen dan 3 wadah pasir.

3. Rendam bata merah yang telah dipotong menjadi dua bagian sampai jenuh.

4. Letakkan bata merah dalam alat cetakan untuk di capping setebal $6 \mathrm{~mm}$.

5. Capping bata setebal $6 \mathrm{~mm}$ menggunakan adukan mortar. 
6. Lepaskan bata dari cetakan capping keesokkan harinya, lalu rendam dalam air bersih selama 24 jam.

7. Angkat bata dari bak perendaman, bidang-bidangnya diseka dengan kain lembab.

8. Ukur dimensi bata untuk mendapatkan luas penampang benda uji yang dilakukan uji tekan.

9. Pengujian kuat tekan dilakukan menggunakan alat compression machine hand operated kapasitas $250 \mathrm{kN}$.

\section{HASIL DAN PEMBAHASAN}

\section{Kuat tekan bata merah}

Bata merah yang diuji kuat tekan terlebih dahulu dicapping supaya permukaan bata merah rata. Hasil uji kuat tekan bata merah dapat dilihat pada Tabel 4. Grafik pengaruh penambahan fly ash dan abu sekam padi terhadap kuat tekan dapat dilihat pada Gambar 1. Grafik hubungan antara kadar air adukan tanah liat pembentuk bata dan kuat tekan bata merah dapat dilihat pada Gambar 2.

Tabel 4. Hasil Uji Tekan Bata

\begin{tabular}{|c|c|c|}
\hline No & Benda Uji & Kuat Tekan $\left(\mathrm{kg} / \mathrm{cm}^{2}\right)$ \\
\hline 1 & B0 & 38,97 \\
\hline 2 & B5 & 36,64 \\
\hline 3 & B10 & 35,86 \\
\hline 4 & B15 & 34,89 \\
\hline 5 & B20 & 30,93 \\
\hline 6 & B25 & 29,00 \\
\hline 7 & B30 & 20,25 \\
\hline
\end{tabular}

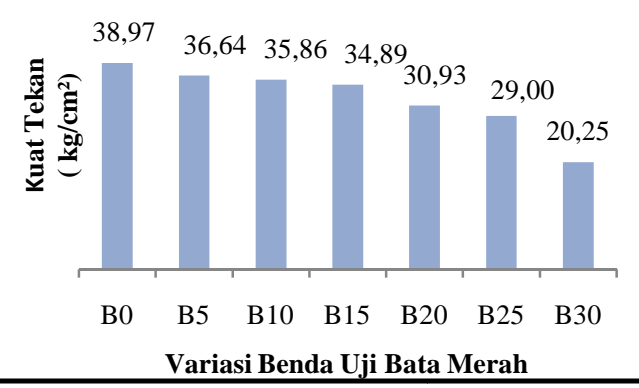

Gambar 1. Diagram Hasil Pengujian Kuat Tekan Bata Merah

Jurnal Inersia April 2018 Vol.10 No.1

Email:Inersia@unib.ac.id
Penurunan kuat tekan dari bata normal berkisar antara $5,98 \%$ sampai $48,04 \%$. Nilai kuat tekan terbesar berada pada benda uji bata normal sebesar $38,97 \mathrm{~kg} / \mathrm{cm}^{2}$. Nilai kuat tekan terkecil pada benda uji penambahan abu masing-masing $30 \%$ yaitu $20,25 \mathrm{~kg} / \mathrm{cm}^{2}$.

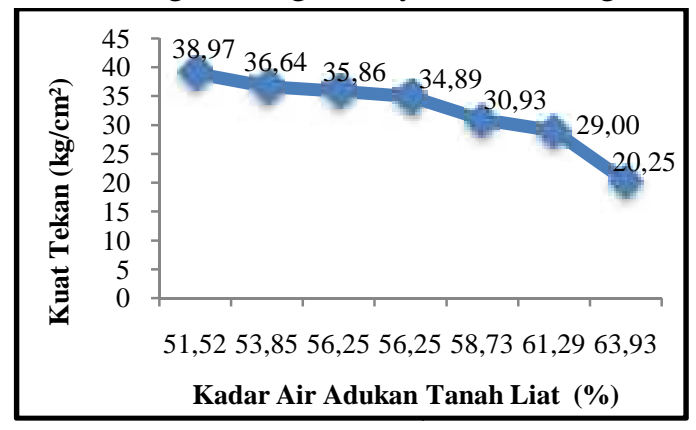

Gambar 2. Grafik Hubungan Kadar Air Adukan Tanah Liat dan Kuat Tekan Bata Merah

Nilai kuat tekan sangat berpengaruh pada penambahan abu dan jumlah penggunaan air adukan tanah liat pembentuk bata. Penambahan abu dan jumlah penggunaan air adukan tanah liat pembentuk bata menyebabkan nilai kadar air adukan tanah liat meningkat dan menimbulkan rongga sehingga kuat tekan yang dihasilkan semakin menurun.

\section{KESIMPULAN}

Kesimpulan dari penelitian pengaruh penambahan fly ash dan abu sekam padi terhadap nilai kuat tekan pada bata merah pejal konvensional yang telah dilakukan adalah sebagai berikut:

1. Nilai kuat tekan dipengaruhi oleh penambahan abu dan banyaknya penggunaan air adukan tanah liat pembentuk bata. Penambahan abu dan jumlah penggunaan air adukan tanah liat menyebabkan nilai kadar air adukan tanah liat pembentuk bata meningkat dan menimbulkan rongga membuat nilai kuat tekan bata semakin menurun.

2. Kuat tekan bata merah dengan penambahan abu 30\% mengalami penurunan terbesar dari bata normal $\left(20,25 \mathrm{~kg} / \mathrm{cm}^{2}\right)$ persen penurunan 
$(48,04 \%)$ dan penurunan terkecil terdapat pada bata merah dengan penambahan abu $5 \%\left(36,64 \mathrm{~kg} / \mathrm{cm}^{2}\right)$ persen penurunan $(5,98 \%)$.

\section{DAFTAR PUSTAKA}

Armeyn., 2014, Kuat Tekan Beton dengan Fly Ash Ex. PLTU Sijantang Sawahlunto, Jurnal Momentum, Vol. 16, 24-33.

Astuti, A., 1997, Tanah Liat, http://axzx.blogspot.com/2008/12/proses -pembentukan-tanah-liat-html. 07 Juni 2017, Pkl 20.00 WIB.

Elianora, Shalahuddin, M., dan Aljirzaid., 2010, Variasi Tanah Lempung, Tanah Lanau, dan Pasir sebagai Bahan Campuran Batu Bata, Jurnal Teknobiologi, Fakultas Teknik, Universitas Riau, Pekanbaru.

Ferdyan., dan Aswad, H.N., 2013, Penggunaan Limbah Las Pabrik dan Abu Sekam Padi sebagai Bahan Subtitusi Semen pada Paving Block, Jurnal Metropilar Vol. II No. 3 juli 2013, Haluoleo.

Kamali, L., 2014, Pengaruh Penambahan Abu Sabut Kelapa pada Pembuatan Batu Bata tanpa Pembakaran terhadap Kuat Tekan dan Porositas, Universitas Gorontalo, Gorontalo.

Sari, H. A., 2014, Analisis Penyusutan dan Absorpsi Bata Merah Pejal Konvensional di Kecamatan Selebar dan Muara Bangkahulu Kota Bengkulu, Jurusan Teknik Sipil, Fakultas Teknik, Universitas Bengkulu, Bengkulu.

SNI 03-1965-1990, 1990, Metode Pengujian Kadar Air Tanah, BSN.

SNI 03-3637-1994, 1994, Metode Pengujian Berat Isi Tanah Berbutir Halus dengan Cetakan Benda Uji, P.U. Balibang.

SNI 03-4804-1998, 1998, Metode Pengujian Bobot Isi dan Rongga Udara dalam Agregat, Pekerjaan Umum, Jakarta.

SNI 1964-2008, 2008, Cara Uji Berat Jenis Tanah, BSN.

SNI 1965-2008, 2008, Cara Uji Penentuan Batas Plastis dan Indeks Plastisitas Tanah, BSN.

SNI 3423-2008, 2008, Cara Uji Analisis Ukuran Butir Tanah, BSN.

SNI 15-2094-2000, 2000, Tentang Bata Merah Pejal, Pekerjaan Umum, Jakarta. 
ISSN 2086-9045

Jurnal Inersia April 2018 Vol.10 No.1 